\title{
Construction of online Monitoring System and Monitoring Data Analysis for Tailings in Alpine Region
}

\author{
Quan-ming LI ${ }^{1, a}$, Hong ZHANG ${ }^{2, b}$ and Zhao YANG ${ }^{2, c}$ \\ ${ }^{1}$ China Academy of Safety and Science \& Technology, Beijing, China, 100012 \\ ${ }^{2}$ North China Institute of Science \& Technology, Langfang, China, 101601 \\ a454968503@qq.com, b1359243783@qq.com, c1690814870@qq.com
}

\begin{abstract}
Keywords: Tailings pond; online Monitoring System; R/S method; Hurst Index
Abstract: Chinese alpine regions experience strong sunshine, large temperature differences, prolonged low temperature and other conditions. Tailings melting caused by tailings spring flood season, in winter and spring alternately, can easily result in dam collapse. According to the characteristics of climate and temperature differences in the alpine region, there is great utility in analyzing the stability of the tailings dam, slope future trend and preventing tailings dam failure by designing and constructing a tailings pond online monitoring system suitable for alpine regions. A system capable of monitoring accurately under extreme weather conditions could track and transmit data, in real time, describing the changes of saturation line, displacement and settlement of the tailings. In this paper we establish an online monitoring system suitable for the alpine region in Inner Mongolia and analyze tailings online monitoring data from 2015 to 2016 to judge dam operation trends. By calculating the Hurst index and the average cycle period based on R/S method, we reached the conclusion that there is a long-term memory and persistence for the time series data of the monitoring point. The average cycle of the monitoring point can provide theoretical support for informing future trends of the monitoring points of the dam.
\end{abstract}

\section{Introduction}

Chinese alpine regions experience strong sunshine, large temperature fluctuations, low temperatures, low pressure, lots of sand and other characteristics. As winter transitions into spring, the pulp melting can easily lead to tailings reservoir spring flood, causing dam collapse. The permafrost in the alpine region can be divided into three types: hard permafrost, hard permafrost or loose permafrost, and loose permafrost [1]. According to the characteristics of climate and temperature difference in alpine regions, there is great significance in analyzing the stability of the tailings dam, slope future trend and preventing tailings dam failure by designing and constructing a tailings pond online monitoring system suitable for alpine regions. This system would be capable of accurate monitoring under extreme weather conditions, and the timely transmission of data that would inform changes of saturation line, displacement and settlement of the tailings.

According to the regulations of "Code for design of tailings facilities" and "Safety technical regulations for the tailing pond", the Third and above of the tailings pond must have an established online monitoring system. The Fourth pond should be tracked on the online monitoring system. At the end of 2015, 1,168 tailings ponds had been established on the online monitoring system out of the 8,869 in China. This enabled timely monitoring of the tailings reservoir water level, infiltration line depth, dam displacement, dry beach length and other essential safety production indicators. At the same time, according to the requirements of the "Technical regulations for the tailings pond safety monitoring", the monitoring of the dam displacement cross section, as a part of the online monitoring system, should be focused on the highest cross section of the dam, the cross-section of the drainage pipe, the region of the relatively greater geological change in foundation and the regions where there are functional abnormalities.

In this paper, a valley tailings pond was sampled in Inner Mongolia. It has an established online monitoring system to monitor tailings reservoir infiltration line, displacement, sedimentation and other changes as well as detecting abnormal data. We extracted the online monitoring data from 2015 
to 2016, combined with fractal theory R/S analysis method for statistical analysis [2,3]. The results of the statistical analysis can determine the variation law and stability trend of the slope and provide theoretical support for the safe operation of the tailings dam.

\section{Design and Establish an Online Monitoring System in the Alpine Region}

Inner Mongolia is situated in North China. It is a highland landscape area with an average altitude of around 1,000 meters. This area experiences strong winds, lots of sand, low pressure, severe changes in summer and winter etc. The annual average temperature is $32 \sim 46.4 \mathrm{~F}$. The annual average temperature difference is $93.2 \sim 96.8 \mathrm{~F}$. The daily average temperature difference is $53.6 \sim 60.8 \mathrm{~F}$. The winter minimum temperature is $-22 \sim-40 \mathrm{~F}$. A prolonged low-temperature environment can easily lead to monitoring equipment damage caused by equipment start difficulty and high heat. High wind level may also influence monitoring accuracy due to equipment instability. We have designed and established an online monitoring system design scheme suitable for the alpine region combined with the ecological characteristics of Inner Mongolia to ensure the long-term and effective operation of the online monitoring system. Taking tailings pond in Inner Mongolia as an example; tailings dam length $1,140 \mathrm{~m}$, height $52 \mathrm{~m}$, crest elevation $770 \mathrm{~m}$, inner and outer slope ratio 1:2.5. The tailings landform belongs to low hills, with flat terrain. There is grassland and perennial without water and the slope on both sides is between $5^{\circ}$ and $10^{\circ}$. The main catchment area is $9.56 \mathrm{~km}^{2}$ with a ditch slope grade of $2.0 \%$. The foundation soil is mainly composed of cultivated soil, residual soil, strong weathered granite, middle weathered granite and weathered granite. The total capacity of the tailings is $574,730,000 \mathrm{~m}^{3}$, and the tailings are constructed by a one-time damming method. The tailings ponds automatic safety monitoring and warning system was established, combined with the geological characteristics, reservoir capacity, dam height and dam type, based on the profile setting principle of the tailings pond online monitoring system. This system has monitored project subsystems including dam surface displacement, settlement displacement, infiltration line, rainfall, and video monitoring subsystems etc. The system equipment style and monitoring point numbers are provided in Table 1. The monitoring system is composed of five monitoring profiles. There are five surface displacement monitoring points at elevation $774 \mathrm{~m}$ and $770 \mathrm{~m}$ (Fig. 1), and five infiltration line monitoring points (Fig. 2). There are 10 internal displacement monitoring points at elevation 770m. The system has been setting 13 video monitoring points to monitor all-weather across the whole body of the dam, back to the pool, pumping room, total station monitoring room and other key parts. The minimum winter temperature in Inner Mongolia is close to $-40 \mathrm{~F}$, the current commonly used total station operating temperature is $-4 \sim 122 \mathrm{~F}$. It is difficult for the total station to run normally under cold weather conditions. In order to ensure the accuracy of equipment, a total station observation room was constructed for setting the observation base of the total station. Rainfall monitoring equipment is located near the total station observation room. All sensor monitoring data of the monitoring system are transmitted to the monitoring center data server through optical fiber communication. The data server can be time or real-time to enable data acquisition and analysis, data processing, storage and backup etc. 
Table 1. Tailings online monitoring equipment configuration and monitoring point scale

\begin{tabular}{|c|c|c|}
\hline No. & Project & Equipment and monitoring point setting \\
\hline 1 & Surface displacement & Precision total station, 12 \\
\hline 2 & Settlement displacement & In-clinometer, 10 \\
\hline 3 & Rainfall & Tipping bucket rain gauge, 1 \\
\hline 4 & Video Surveillance & Dome camera and night vision, 13 \\
\hline 5 & Infiltration line & Vibrating wire pressure gauge, 5 \\
\hline 6 & Lightning protection system & 1 \\
\hline 7 & Power supply system & 1 \\
\hline 8 & Communication system & 1 \\
\hline 9 & Monitoring center & 1 \\
\hline & Itotal & $\begin{array}{l}\text { Water level } \\
\text { monitoring tower } \\
\text { Solar cell }\end{array}$ \\
\hline
\end{tabular}

Fig. 1. Tailings monitoring point

Fig. 2. Infiltration line monitoring points

According to the actual situation of the tailings pond, the comprehensive warning management upper computer system is set up in the enrichment plant monitoring room. The online monitoring system includes data server, monitoring and warning software system, a monitoring and surveillance display system as well as other supporting facilities. The monitoring room can display monitoring and warning software and site video image information. The online monitoring system network topology is shown in Fig. 3. Combined with the requirement of work needed in the tailings region, various functions, which allow the monthly report of tailings, were added to the initial monitoring system software. The system allowed excel print and a summary of the list of export equipment.

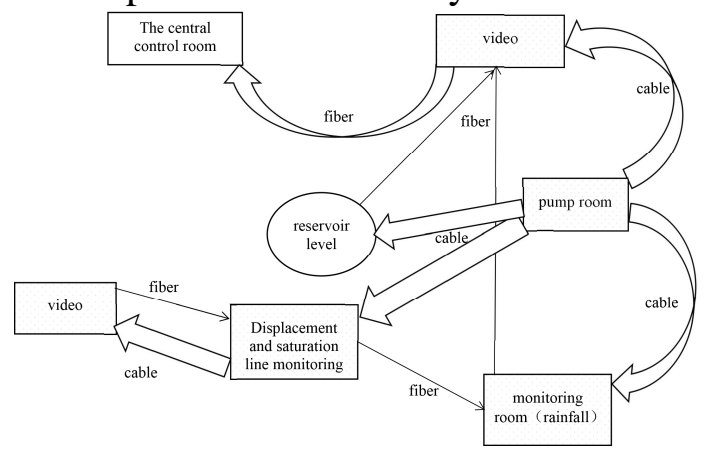

Fig. 3. Tailings online monitoring system network topology

\section{Monitoring Displacement Data Analysis}

The dam slope surface displacement and settlement data based on the monitoring data of G21, G31 and G41 during 2015 to 2016 was analyzed, as shown in Fig. 4. It can be seen from Fig. 4, from January 2015 to January 2016, that the slope surface displacement and settlement increased close to 
the average speed, indicating that the dam during the monitoring period was stable. Between March 2016 and June 2016, there was a more drastic fluctuation in the surface displacement of the monitoring points. The maximum displacement of the surface is $0.66 \mathrm{~mm}$, while the maximum displacement of the settlement increased to 286mm. From July 2016 to December 2016, the surface displacement and settlement stability no longer depict a large change as the dam tends to stabilize the state.
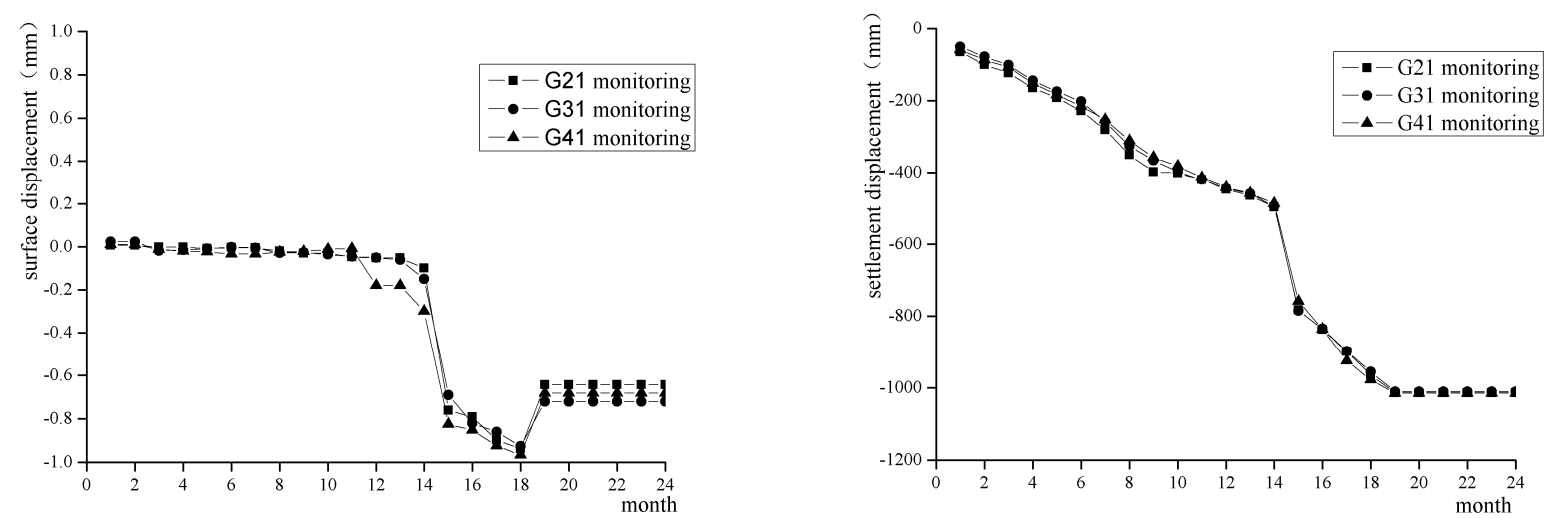

Fig. 4. G21, G31, G41 displacement data chart

Combined with the relevant databases from enterprises, the large Ikeda method, which utilizes the mold bag construction method, was applied to the tailings in 2016. This method increased the height by $5 \mathrm{~m}$ and formed a balanced load on the base of the original accumulated dam. It can form a uniform load on the basis of the original accumulation dam. Under the action of the load, large settlement accumulation and settlement difference occurred in the initial stage of the accumulation dam, resulting in the sudden increase of the monitoring data value. With the tailings dam force to achieve a balance, settlement and surface displacement gradually stabilized.

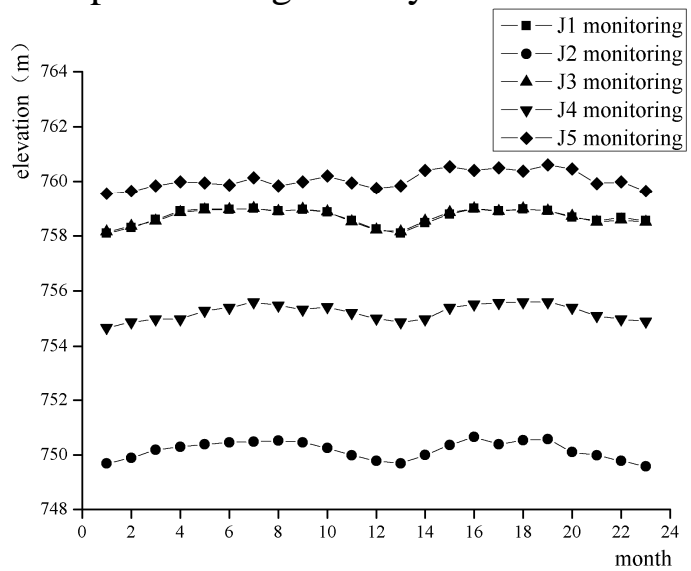

Fig. 5. Infiltration line elevation change chart

The variation of the tailings infiltration line in 2015 2016 is illustrated in Fig. 5. The fluctuation of the infiltration line is related to the local temperature and ore discharge. The overall variation of the infiltration line is stable and has no significant change because of 2015 2016 enterprises on the amount of ore. The average annual temperature of the reservoir area shows no major changes when querying the monthly data of the enterprise and the monthly average temperature data of the tailings.

\section{Monitoring Data Analysis by R/S Analysis Method}

The R/S analysis method, also known as the standard deviation analysis method, is a time series statistical method proposed by Hurst index. The Hurst index calculated by this method embodies the autocorrelation of time series, especially reflecting the long term hidden in the sequence trend and long-term memory. $\mathrm{H}>0.5$, means the memory is strong, continuing to maintain the existing trend that the possibility quality is strong. $\mathrm{H}<0.5$ indicates that the memory is weakened and the trend 
begins to reverse. The closer the Hurst index value is to 0.5 , the stronger the time series randomness, so the direction can not be determined [4,5].

In the Hurst index, the statistical V(n) is introduced simultaneously, and the average cycle of the time series is quantitatively described. It is possible to determine whether the time series has periodic cycles and estimates the period length. The average cycle period can represent the average memory length of the system for the initial condition [6-8].

According to the Hurst index calculation principle, we calculated the Hurst index and used the second order least squares method to linearly analyze the data. The results of the linear fitting of the tailings dam monitoring point settlement are shown in Fig. 6. Hurst index of G21, G31 and G41 are 0.694, 0.691 and 0.691, respectively, which were more than 0.5 , indicating that there was long-term memory and persistence in the time series of dam settlement. The variation trend of $V(n)-\lg (n)$ is also shown in Fig 6, and the graph shows an upward trend indicating that there is long-term memory in the time series of sedimentation, which is the disappearance point of the curve, which corresponds to the time series. The average cycle period of the settlement time series is 6 months, and the sedimentation time series will lose dependence on the initial conditions after 6 months.
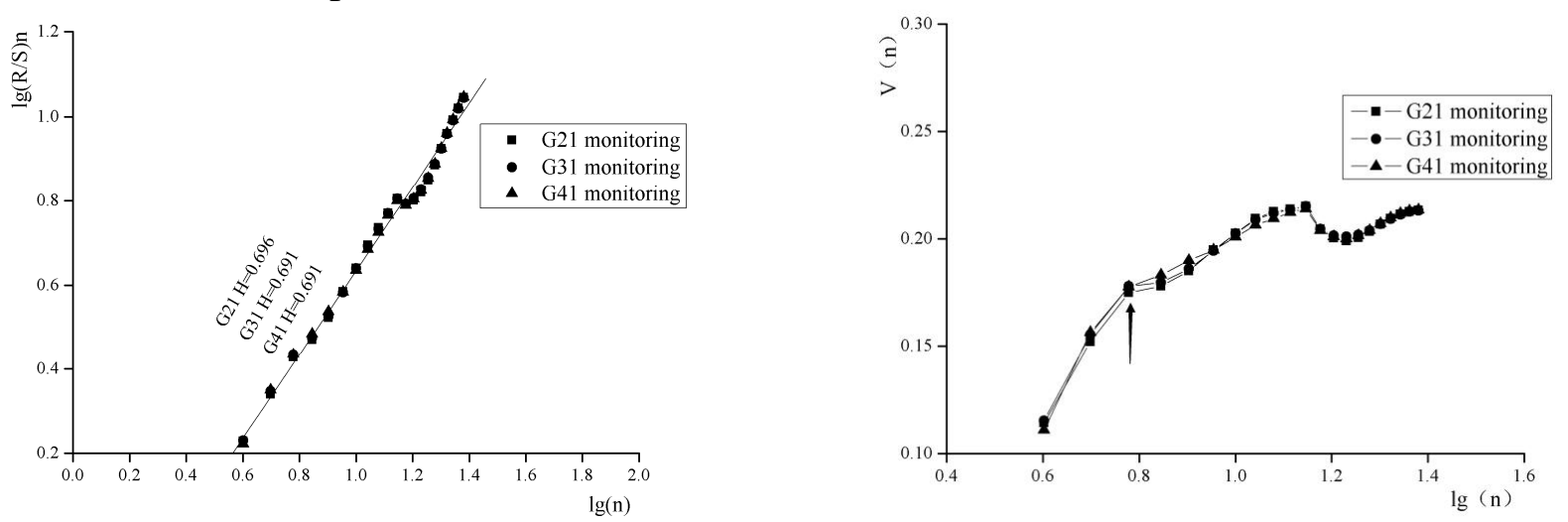

Fig. 6. Settlement analysis results of R/S and V(n)

The results of the Hurst index and the average cycle of the online monitoring project are shown in Table 2.

Table 2. R/S analysis results of each monitoring point of tailings dam

\begin{tabular}{cccccc}
\hline Project & Monitoring & Hurst & $\mathrm{R}^{2}$ & Residual square sum & Cycle(month) \\
\hline \multirow{2}{*}{$\begin{array}{c}\text { Surface } \\
\text { displacement }\end{array}$} & $\mathrm{G} 21$ & 0.693 & 0.823 & 0.080 & 7 \\
\cline { 2 - 6 } & $\mathrm{G} 31$ & 0.686 & 0.816 & 0.087 & 7 \\
\cline { 2 - 6 } Settlement & $\mathrm{G} 41$ & 0.670 & 0.826 & 0.076 & 6 \\
\cline { 2 - 6 } displacement & $\mathrm{G} 21$ & 0.694 & 0.829 & 0.011 & 6 \\
\cline { 2 - 6 } & $\mathrm{G} 31$ & 0.691 & 0.801 & 0.009 & 6 \\
\hline & $\mathrm{G} 41$ & 0.691 & 0.811 & 0.009 & 6 \\
\cline { 2 - 6 } & $\mathrm{J} 1$ & 0.730 & 0.844 & 0.102 & 8 \\
\cline { 2 - 6 } Infiltration line & $\mathrm{J} 2$ & 0.710 & 0.823 & 0.124 & 8 \\
\cline { 2 - 6 } & $\mathrm{J} 3$ & 0.722 & 0.814 & 0.113 & 11 \\
\cline { 2 - 6 } & $\mathrm{J} 4$ & 0.749 & 0.865 & 0.110 & 8 \\
\hline
\end{tabular}

It can be seen from the Table 2 that the Hurst value of the tailings dam monitoring point is greater than 0.5 , indicating that the time data sequence has a continuous correlation, where the surface displacement and sedimentation displacement $\mathrm{H}$ value are between 0.6 to 0.7 , lower than infiltration line $\mathrm{H}$ value, this indicates that the surface displacement and sedimentation displacement are highly random; the latter part of the data sustainability is weak. According to the average cycle data, we can see that the time series has periodic cycle, the surface displacement cycle of the monitoring point is about 7 months, the resetting cycle of the monitoring point is about 6 months, and the circulation 
period of the infiltration line is about 8 months. Point nearly 6 to 8 months of operation can be predicted; the dam in the future cycle remains stable.

\section{Conclusions}

According to the climatic characteristics of alpine regions in China, a tailings reservoir online monitoring system for alpine region was established in Inner Mongolia and the monitoring data from 2015 to 2016 was extracted to analyze the slope displacement, cumulative settlement and infiltration line height variation. Using $\mathrm{R} / \mathrm{S}$ analysis to determine the correlation between the dam data and predict the future operation of the dam, the conclusions are as follows:

1) In view of the low temperature and high wind power in the alpine regions of China, the observation room of the total station was established to solve problems such as the difficulty starting under the low temperature in winter, the high heat damage, equipment dumping under the wind and the difficulty of ensuring the monitoring.

2) By analyzing the surface displacement, settlement displacement and infiltration line of each monitoring point, it can be seen that the dams have large change on settlement displacement and surface displacement during accumulated dam height. With the dam force to rebalance, the settlement and surface displacement gradually become smaller until steady.

3) Using the R/S analysis method to analyze the monitoring data of surface displacement, settlement and infiltration line can find that monitoring time series data has a significant sustained effect; monitoring data has long-term memory and continuity.

4) Calculating the average cycle of the monitoring data, and providing theoretical support for predicting the future trend of the monitoring points of the dam.

\section{Acknowledgements}

This research project was made possible through the financial support from the project NO. 71373245 by the National Natural Science Foundation of China, and NO.3142017041 by School science and technology fund of North China Institute of Science.

\section{References}

[1] Liu Shiqiao, Chen Zhangyou, Zhang Zeng: Engineering Construction, Vol. (2008), p. 22-26.

[2] Sun Xia, Wu Ziqin, Huang Yun: Fractal Principle and Application, (Press of University of Science and Technology of China, China 2003).

[3] Zhou Xiaobo, Naraine Persaud, H. WANG: Hydrology and earth system sciences, Vol. 10 (2006), p. 79-91.

[4] Li Yuanyao, Yin Kunlong, Cheng Wenming: Chinese Journal of Geotechnical Engineering, Vol. 32 (2010), p. 1291-1296.

[5] Zhang Zilong, Liu Zhu, Chen Xingpeng, et al: Economic Geography, Vol. 33 (2013), p. 20-25.

[6] Li Jianlin, Zan Mingjun, Zheng Jidong, et al: Journal of Henan Polytechnic University, Vol. 34 (2015), p. 472-476.

[7] Li Jianlin, Zan Mingjun, Li Baoling: Areal Research and Development, Vol. 33 (2014), p. 127-131.

[8] Zheng Liyuan: Shanxi Architecture, Vol. 43 (2017), p. 108-109. 